\title{
Untangling the Debate: The Ethics of Human Enhancement
}

\author{
Patrick Lin • Fritz Allhoff
}

\begin{abstract}
Human enhancement, in which nanotechnology is expected to play a major role, continues to be a highly contentious ethical debate, with experts on both sides calling it the single most important issue facing science and society in this brave, new century. This paper is a broad introduction to the symposium herein that explores a range of perspectives related to that debate. We will discuss what human enhancement is and its apparent contrast to therapy; and we will begin to tease apart the myriad intertwined issues that arise in the debate: (1) freedom \& autonomy, (2) health \& safety, (3) fairness \& equity, (4) societal disruption, and (5) human dignity.
\end{abstract}

P. Lin

Dept. of Philosophy, California Polytechnic State Univ., San Luis Obispo, CA 93407, USA

P. Lin $(\bowtie)$

Dept. of Philosophy, Dartmouth College,

Hanover, NH 03755, USA

e-mail: patrick@nanoethics.org

F. Allhoff

Dept. of Philosophy, Western Michigan Univ., 3004 Moore Hall,

Kalamazoo, MI 49008, USA

e-mail: fritz.allhoff@wmich.edu

F. Allhoff

Centre for Applied Philosophy \& Public Ethics, The Australian National University, LPO Box 8260, Canberra ACT 2601, Australia e-mail: fritz.allhoff@anu.edu.au
Keywords Nanotechnology Human enhancement . Ethics · Society · Freedom · Autonomy · Health .

Safety $\cdot$ Fairness $\cdot$ Equity $\cdot$ Disruption $\cdot$ Dignity

\section{Introduction}

Homo sapiens has been such a prolific species, simply because we are very good at relentlessly adapting to our environment. At the most basic level, we have won control over fire and tools to forge a new world around us, we build shelter and weave clothes to repel the brutal elements, and we raise animals and crops for predictability in our meals. With our intellect and resourcefulness, we are thereby better able to survive this world.

However, it is not just the world around us that we desire to change. Since the beginning of history, we also have wanted to become more than human, to become Homo superior. From the godlike command of Gilgamesh, to the lofty ambitions of Icarus, to the preternatural strength of Beowulf, to the mythical skills of Shaolin monks, and to various shamans and shapeshifters throughout the world's cultural history, we have dreamt - and still dream-of transforming ourselves to overcome our all-too-human limitations.

In practice, this means that we improve our minds through education, disciplined thinking, and meditation; we improve our bodies with a sound diet and physical exercise; and we train with weapons and techniques to defend ourselves from those who would conspire to kill. But today, something seems to be different. With ongoing work to unravel the mysteries of our minds 
and bodies, coupled with the art and science of emerging technologies, we are near the start of the Human Enhancement (or Engineering) Revolution.

Now we are not limited to "natural" methods to enhance ourselves or to merely wield tools such as a hammer or binoculars or a calculator. We are beginning to incorporate technology within our very bodies, which may hold moral significance that we need to consider. These technologies promise great benefits for humanity - such as increased productivity and creativity, longer lives, more serenity, stronger bodies and minds, and more - though, as we will discuss later, there is a question whether these things translate into happier lives, which many see as the point of it all $[42,40]$.

As examples of emerging technologies, in early 2008, a couple imaginative inventions in particular, among many, are closing the gap even more between science fiction and the real world. Scientists have conceptualized an electronic-packed contact lens that may provide the wearer with telescopic and night vision or act as an omnipresent digital monitor to receive and relay information [39]. Another innovation is a touch display designed to be implanted just under the skin that would activate special tattoo ink on one's arm to form images, such as telephonenumber keys to punch or even a video to watch [34]. Together with ever-shrinking computing devices, we appear to be moving closer to cybernetic organisms (or "cyborgs"), that is, where machines are integrated with our bodies or at least with our clothing in the nearer-term. Forget about Pocket PCs, mobile phones, GPS devices, and other portable gadgets; we might soon be able to communicate and access those capabilities without having to carry any external device, thus raising our productivity, efficiency, response time, and other desirable measures-in short, enabling us to even better survive our world.

Technology is clearly a game-changing field. The inventions of such things as the printing press, gunpowder, automobiles, computers, vaccines, and so on, have profoundly changed the world, for the better we hope. But at the same time, they have also led to unforeseen consequences, or perhaps consequences that might have been foreseen and addressed had we bothered to investigate them. Least of all, they have disrupted the status quo, which is not necessarily a terrible thing in and of itself; but unnecessary and dramatic disruptions, such as mass displacements of workers or industries, have real human costs to them.
As we will discuss, such may be the case as well with human enhancement technologies, enabled by advances in nanotechnology, micro-electro-mechanical systems (MEMS), genetic engineering, robotics, cognitive science, information technology, pharmacology, and other fields [45]. ${ }^{1}$

In this special issue of NanoEthics: Ethics for Technologies that Converge on the Nanoscale, we present several papers that examine many ethical and social issues surrounding human enhancement technologies, especially driven by nanotechnology. For instance, on the issue of whether such technologies ought to be regulated or otherwise restricted, one position is that (more than minimal) regulation would hinder personal freedom or autonomy, infringing on some natural or political right to improve our own bodies, minds, and lives as we see fit $[3,6,21,36]$. Others, however, advocate strong regulation - and even a research moratorium - to protect against unintended effects on society, such as the presumably-undesirable creation of a new class of enhanced persons who could outwit, outplay, and outlast "normal" or unenhanced persons for jobs, in schools, at sporting contests, and so on, among other reasons [16-18]. Still others seek a sensible middle path between stringent regulation and individual liberty $[25,19]$.

No matter where one is aligned on this issue, it is clear that the human enhancement debate is a deeply passionate and personal one, striking at the heart of what it means to be human. Some see it as a way to fulfill or even transcend our potential; others see it as a darker path towards becoming Frankenstein's monster. But before more fully presenting those issues, it would be helpful to lay out some background and context to better frame the discussion, as follows.

\section{Definitions}

First, we need to draw several important distinctions. ${ }^{2}$ Strictly speaking, "human enhancement" includes any activity by which we improve our bodies, minds, or

\footnotetext{
${ }^{1}$ For an overview of ethical and social issues beyond nanotechnology's role in human enhancement, see [1, 30, 32].

${ }^{2}$ We recognize that some advocates of human enhancement argue against making such a distinction (e.g., [7]), which seems to serve to more easily justify unrestricted human enhancement; even if this position is tenable, we do not want to take that point for granted here, which we will discuss below.
} 
abilities - things we do to enhance our welfare. So reading a book, eating vegetables, doing homework, and exercising may count as enhancing ourselves, though we do not mean the term this way in our discussion here. These so-called "natural" human enhancements are morally uninteresting because they appear to be unproblematic to the extent that it is difficult to see why we should not be permitted to improve ourselves through diet, education, physical training, and so on.

Rather, allow us to stipulate for the moment that "human enhancement" is about boosting our capabilities beyond the species-typical level or statisticallynormal range of functioning for an individual [8]. Relatedly, "human enhancement" can be understood to be different from "therapy", which is about treatments aimed at pathologies that compromise health or reduce one's level of functioning below this speciestypical or statistically-normal level [27]. Another way to think about human enhancement technologies, as opposed to therapy, is that they change the structure and function of the body [19]. Admittedly, none of these definitions is immune to objections, but they are nevertheless useful as a starting point in thinking about the distinction, including whether there really is such a distinction.

Thus, corrective eyeglasses, for instance, would be considered therapeutic rather than enhancement, since they serve to bring your vision back to normal; but strapping on a pair of night-vision binoculars would count as human enhancement, because they give you sight beyond the range of any unassisted human vision. As another example, using steroids to help muscular dystrophy patients regain lost strength is a case of therapy; but steroid use by otherwise-healthy athletes would give them new strength beyond what humans typically have (thereby enabling them to set new performance records in sports). And growing or implanting webbing between one's fingers and toes to enable better swimming changes the structure and function of those body parts, counting then as a case of human enhancement and not therapy.

Likewise, as it concerns the mind, taking Ritalin to treat attention-deficit hyperactivity disorder (ADHD) is aimed at correcting the deficit; but taken by otherwise-normal students to enable them to focus better in studying for exams is a form of human enhancement. And where reading a book may indeed make you more knowledgeable, it does not make you so much smarter than most everyone else or push your intellect past natural limits; on the other hand, a computer chip implanted into your brain that gives you direct access to Google or spreadsheets would provide mental capabilities beyond the species-typical level.

The last example suggests a further distinction we should make. By "human enhancement" we do not mean the mere use of tools; that would render the concept impotent, turning nearly everything we do into cases of human enhancement. But if and when these tools are integrated into our bodies, rather than employed externally, then we will consider them to be instances of human enhancement. Of course, this raises the question: what is so special about incorporating tools as part of our bodies, as opposed to merely using them externally to the body [7]? That is, why should the former count as human enhancement, but not the latter? A neural implant that gives access to Google and the rest of the online world does not seem to be different in kind to using a laptop computer or Pocket PC to access the same, so why should it matter that we are imbedding computing power into our heads rather than carrying the same capabilities with us by way of external devices?

We will not attempt to give a full discussion of that point here, though it will be important to explore the issue further, except to suggest that integrating tools into our bodies (and perhaps with our everyday clothing to the extent that we are rarely without our clothes) appears to give us unprecedented advantages which may be morally significant. These advantages are that we would have easier, immediate, and "always-on" access to those new capabilities as if they were a natural part of our being; we would never be without those devices, as we might forget to bring a laptop computer with us to a meeting. And assimilating tools with our persons creates an intimate or enhanced connection with our tools that evolves our notion of personal identity, more so than simply owning things (as wearing name-brand clothes might boost our sense of self). This may translate into a substantial advantage for the enhanced person, more so than gained by purchasing an office computer or reading books or training with the best coaches.

\section{The Therapy-Enhancement Distinction}

Returning to an issue previously raised, some scholars have reasonably objected to, or at least raised 
difficulties with, the distinctions above; that is, they argue that there is no real distinction between therapy and enhancement. For instance, how should we think about vaccinations: are they a form of therapy, or are they an enhancement of our immune system [7, 8, 21]? On one hand, a vaccination seems to be an enhancement in that there is no existing pathology it is attempting to cure, merely a possible or likely pathology we wish to avoid; but we are drawn to declare it as some form of therapy-perhaps preventative therapy-given its close association with medicine? And if enhancements in general are ultimately found to be socially or ethically problematic, then counting vaccinations as enhancement opens the possibility that it should be regulated or restricted, which would create a serious public health disaster as well as a counterexample to the claim that enhancements are problematic. Thus, even critics of human enhancement may be loathe to put vaccinations in the enhancement bucket, though there does not seem to be an obviously superior reason to think otherwise.

Another dilemma: If a genius were to sustain a head injury, thereby reducing her IQ to merely the "average" or "species-normal" range, would raising her intelligence back to its initial "genius" level count as therapy or enhancement [7]? Either one would seem plausible, but is there a non-arbitrary reason for answering the question either way? If an enhancement, then how do we explain the difference between that and a clear (or clearer) case of therapy in which we return an "average" person who sustains a head injury back to the "normal" IQ range?

The therapy-enhancement distinction holds real stakes, beyond athletic and academic competition. Recent news reports show that the US military is increasingly prescribing anti-depressants to soldiers in combat to alleviate post-traumatic stress as well as stimulants to counteract sleep deprivation-actions which could be viewed as either creating a more effective, level-headed soldier or returning the soldier to the initial "normal" state of combat readiness, further blurring the distinction $[46,50] .^{3}$

The above cases notwithstanding, we would agree that there are difficulties in precisely defining "human

\footnotetext{
${ }^{3}$ However, if the military were to prescribe such medications prior to combat, then one could make the case for counting that as an enhancement; but this may take us full circle back to the vaccination question, particularly as soldiers are routinely vaccinated against bio-threats such as anthrax.
}

enhancement" (as there is with making clear definitions of nearly any other concept), but maintaining the enhancement-therapy distinction, at least until it can be more fully explored, is nonetheless important for several reasons:

First, to the extent that pro-enhancement advocates are primarily the ones arguing against the therapyenhancement distinction, if a goal is to engage the anti-enhancement camp, then it would make for a far stronger case to meet those critics on their own ground (i.e., to grant the assumption that such a distinction exists). If it proves overly charitable to grant this assumption such that the pro-enhancement position is too difficult to defend without it, then perhaps more attention needs to be paid in arguing against the distinction in the first place, given that the debate may hinge on this fundamental issue.

Second, by not making these distinctions, specifically between therapy and enhancement, it may be too easy to argue that all forms of human enhancement are morally permissible given that the things we count as therapy are permissible. That is to say, we risk making a straw man argument that does not make a compelling case either for or against any aspect of human enhancement. Again, if the human enhancement debate turns on this distinction, then much more attention should be paid to defending or criticizing the distinction than has been to date.

Third, at least part of the reason that human enhancement is believed to be the most important issue in the 21 st century by both sides of the debate [26] seems to be that it represents a collision between our intuitions and our actions. For instance, critics may believe that human enhancement technologies give an unfair advantage to some persons, fracturing local or global societies (even more) between the haves and have-nots $[17,18,42,49]$. Yet, at the same time, they seem to endorse - to the extent that they have not raised objections to - our use of existing technologies (e.g., mobile phones, computers, Internet) that also seem to countenance the same division to which human enhancement technologies are said to lead us.

As another example, advocates of human enhancement may believe that individual autonomy should trump health and safety concerns, e.g., athletes should be permitted to take steroids or adults should be allowed to take mood-enhancing drugs at will [36, 48]. Yet, at the same time, they do not offer objections to keeping some drugs illegal, such as crystal meth or 
crack cocaine, which becomes an even more complicated dilemma if they advocate legalizing other contraband such as marijuana.

This is not to say that these tensions with our intuitions are irresolvable, but only that "common sense" is at stake for both sides of the debate. And the initial intuition for the overwhelming majority of us is that there $i$ s a therapy-enhancement distinction (since we understand "therapy" and "enhancement" as meaningfully discrete terms, even if some cases do not neatly fit into either category). So it would be more interesting for pro-enhancement advocates to reconcile their position with that intuition, if possible, rather than to reject the distinction, which is less satisfying. Or if the therapy-enhancement distinction really is untenable, then more vigorous argument seems to be needed before we are prepared to cast aside our intuition.

Fourth, the famous philosophical puzzle "The Paradox of the Heap" should be recalled here: Given a heap of sand with $\mathrm{N}$ number of grains of sand, if we remove one grain of sand, we are still left with a heap of sand (that now only has N-1 grains of sand). If we remove one more grain, we are again left with a heap of sand (that now has N-2 grains). If we extend this line of reasoning and continue to remove grains of sand, we see that there is no clear point $\mathrm{P}$ where we can definitely say that a heap of sand exists on one side of $\mathrm{P}$, but less than a heap exists on the other side. In other words, there is no clear distinction between a heap of sand and a less-than-a-heap or even no sand at all. However, the wrong conclusion to draw here is that there is no difference between them or that the distinction between a heap and no-heap should be discarded (or between being bald and having hair, as a variation of the paradox goes). Likewise, it would seem fallacious to conclude that there is no difference between therapy and enhancement or that we should dispense with the distinction. It may still be the case that there is no moral difference between the two, but we cannot arrive at it through the argument that there is no clear defining line or that there are some cases (such as vaccinations, etc.) that make the line fuzzy. As with 'heap', the terms 'therapy' and 'enhancement' may simply be vaguely constructed and require more precision to clarify the distinction.

Therefore, at least for the time being and for the purposes of this paper, we will assume that a therapyenhancement distinction is defensible and illuminative, at least where it aligns with our intuitions.

\section{Scenarios}

Given the above stipulations about what counts as human enhancement, let us lay out a few more scenariosreal, possible, and hypothetical - to further clarify what we mean by human enhancement. We can loosely group these scenarios into three categories: mental performance, physical performance, and other applications.

In the area of improving mental performance, individuals are already using pharmaceuticals available today to achieve such goals as increased productivity, creativity, serenity, and happiness. We previously mentioned Ritalin use, intended for ADHD patients, by otherwise-normal students to boost concentration as a way to study more effectively. In sports, drugs such as beta-blockers, intended to treat high blood pressure and other disorders by slowing down the heart rate, have been used to reduce anxiety as a way to boost physical performance, such as in preparing for an important and nerve-racking putt in golf or steadying an archer's hand to better release the arrow in between heartbeats. In warfare, anti-depressants and stimulants have been used to treat post-traumatic stress and sleep deprivation, thereby creating better, more effective soldiers. And, of course, hallucinogenic and other recreational drugs, including alcohol, continue to be used (and used famously by some authors and artists) to achieve greater creativity, relaxation, and even enlightenment.

In the future, as technology becomes more integrated with our bodies, we can expect neural implants of the kind we mentioned above that effectively puts computer chips into our brains or allows devices to be plugging directly into our heads, giving us always-on access to information as well as unprecedented information-processing powers. New and future virtual reality programs are able to much better simulate activities, for instance, to train law enforcement officers and soldiers in dangerous situations so that they can respond better to similar events in the real world.

In the area of physical performance, steroids use by athletes is one of the most obvious examples. Cosmetic surgery has also grown in popularity, not for corrective purposes but to increase (perceived) attractiveness. Prosthetic limbs have improved to such a degree that they are already enabling its wearer greater than normal strength and capabilities, sparking a debate on whether athletes with those artificial limbs may participate in the Olympics [13]. 
In the future, we can expect continuing advances in robotics and bionanotechnology to give us cybernetic body parts, from bionic arms to artificial noses and ears, that surpass the capabilities of our natural body. Today, research organizations such as MIT's Institute for Soldier Nanotechnologies are working on an exoskeleton to give the wearer superhuman strength as well as flexible battlesuits that can, for instance, harden when needed to create a splint or tourniquet to attend to injuries more quickly and effectively [35]. And we previously mentioned innovative designs such as for a contact lens that enables us to see in the dark or receive information from a miniature digital monitor. Further, designs have already been drawn for even more fantastic innovations such as a respirocyte: an artificial red blood cell that holds a reservoir of oxygen [15]. A respirocyte would come in handy for, say, a heart attack victim to continue breathing for an extra hour until medical treatment is available, despite a lack of blood circulation to the lungs or anywhere else. But in an otherwise-healthy athlete, a respirocyte could boost performance by delivering extra oxygen to the muscles, as if the person were breathing from a pure oxygen tank.

And perhaps as an example of both mental and physical enhancement, we should also consider life extension, whether it comes by curing fatal pathologies (such as cancer) or rejuvenating the body/mind or developing anti-aging medicine, and whether it enables us to live another 20 years or 100 years or 1,000 years (radical life extension). This is a particularly contentious issue in the human engineering debate, not just for obvious concerns related to the burden of overpopulation on quality of life or loss of meaning in life, but also because it seems that we are already - and presumably unproblematically - extending our lives through better nutrition, medicine, exercise, sanitation, and so forth; yet there is something troubling to many about the prospect of radical life extension, even if we can all agree that, in principle, more life is better than less life. We will return to this below.

Other applications include enhancements that may seem gratuitous, such as attempting to physically transform into a lizard by tattooing scales all over one's body and forking one's tongue, or into a cat by implanting whiskers, sharpening teeth and clipping one's ears, or into something other than human with implanted horns in one's forehead; all of these procedures have been done already. In the future, we can envision the possibility that prosthetic flippers, designed today for dolphins, might be requested by humans, along with artificial gills, etc., who want to transform into an aquatic animal. This type of enhancements, of course, brings to the forefront the question whether 'enhancement' is the right word to use in the debate in the first place, as opposed to simply 'human engineering' or a more neutral term that does not imply improvement. Indeed, even in cases where technology boosts mental and physical capabilities, it seems that we cannot predict with any accuracy whether there will be any negative psychological or physiological side-effects that will offset the intended benefits of a particular enhancement. For instance, in drinking alcohol as a mood-enhancer of sorts, we already know that it can hold the unintended effect of a painful hangover; and steroids taken by athletes can have disastrous health consequences.

Moreover, if human enhancement can be ultimately defended, then un-enhancements may seem to be morally permissible as well, if individual autonomy is the most important value to consider in the debate. There are already medical cases in which: individuals want to amputate some healthy limb from their bodies [12]; parents want to stunt the growth of their bedridden child to keep her portable and easier to care for [14]; and deaf parents who specifically want a deaf baby in selecting embryos for in vitro fertilization [11]. Un-enhancements aside, we will continue to use 'enhancement' in this paper for the most part, since there is a presumption that whatever technology is integrated with our bodies will be expected to deliver some net benefit, real or perceived (otherwise, why do it?). Further, we will limit our discussion here primarily to those technologies that enhance human cognitive and physical abilities, rather than seeminglygratuitous procedures or un-enhancements.

\section{The Issues}

Now, given the above understanding of human enhancement, let us tease apart the myriad issues that arise in the debate. These too are loose non-exclusive categories that may overlap with one another, but perhaps are still useful in providing an overview of the debate: (1) freedom \& autonomy; (2) health \& safety; (3) fairness \& equity; (4) societal disruption; (5) human dignity. 
Let us make a couple of preliminary notes. First, just as no one could predict with much accuracy how the Internet Revolution would unfold, raising policy issues from privacy to piracy and beyond, the same is likely true with the Human Engineering Revolution; that is, the framework presented below will undoubtedly evolve over time. However, this does not mean that we should not attempt to address the issues we are able to anticipate. Second, the objective of this paper is neither to anticipate nor fully address any given issue, but simply to broadly sketch the major issues, many of which will be expounded upon by the papers in this symposium. Therefore, the following discussion will raise more questions than it answers in constructing that framework.

\section{Freedom \& Autonomy}

There is perhaps no greater value, at least in democracies, than the cherished concepts of freedom and autonomy. (The distinction between the two is not critical to this discussion, so we will not take the space to give a precise definition here; but allow us to stipulate that, at minimum, both concepts are about negative liberty, or the absence of constraints.) But because freedom and autonomy are central to the issue of human enhancement, they add much fuel to the impassioned debate.

Pro-enhancement advocates have argued against regulating enhancements on the grounds that it would infringe on our fundamental ability to choose how we want to live our own lives $[6,21,36]$. Or, in other words, if enhancing our bodies does not hurt anyone (other than possibly ourselves; more on this in the next section), then why should we be prevented from doing so? This is a common objection-arguing especially against governmental intervention - to any number of proposals that involve regulation, from hiring practices to home improvements to school clothing and so on.

Though freedom and autonomy may be viewed in democracies as "sacred cows" that ought not be corralled, the reality is that we do not have complete freedom or autonomy is the areas of life that we think we do anyway. As examples, freedom of the press and freedom of speech do not protect the individual from charges of libel, slander, or inciting panic by yelling "Fire!" in a crowded theater; our privacy expectations quietly give way to security measures, such as searches on our property and persons at airports or eavesdropping on our communications; and even ancestral homes built by the hands of one's forefathers could be unilaterally seized (and demolished) by the state under eminent domain laws. This is to say that whatever rights we have also imply responsibilities and exist within some particular political system, therefore it is not unreasonable to expect or define certain limits for those rights, especially where they conflict with other rights and obligations.

Maximal freedom is a hallmark of a laissez-faire or minimal state, but a democratic society is not compelled to endorse such a stance, as some political philosophers have suggested (e.g., [37]). Nor would reasonable people necessarily want unrestricted freedom anyway, e.g., no restrictions or background checks for gun ownership. Even the most liberal democracy today understands the value of regulations as a way to enhance our freedom. For instance, our economic system is not truly a "free market": though we may advocate freedom in general, regulations exist not only to protect our rights, but also to create an orderly process that greases the economic wheel, accelerating both innovations and transactions. As a simpler example, by imposing laws on traffic, we can actually increase our freedom: by driving forward on only one side of the road, for instance, we can be (more) assured that we will not be a victim of a head-on collision, which makes driving faster a more sensible proposition.

There is another sense, related to free will, in which cognitive enhancements may be infringing: if an enhancement, such as a mood-altering drug or neural implant, interferes or alters our deliberative process, then it is an open question whether or not we are truly acting freely while under the influence of the enhancement. For instance, a "citizen chip" embedded in the brain might cause us to be unswervingly patriotic and hold different values than we would otherwise have. Further, external pressure by or from peers, employers, competitors, national security, and others also may unduly influence one's decision making. [20].

\section{Health \& Safety}

To justify restrictions on our freedom and autonomy, of course, we would need strong, compelling reasons to offset that prima facie harm; specifically, we need 
to identify conflicting values that ought to be factored into our policymaking. One possible reason is that human enhancement technologies may pose a health risk to the person operated upon, similar to illegal or unprescribed steroids use by athletes: given how precious little we still know about how our brains and other biological systems work, any tinkering with those systems would likely give rise to unintended effects, from mild to most serious [42]. Even drinking pure water-perhaps the safest thing we can do to our own bodies - may have some harms. For example, maybe we become dependent on fluoridated water to prevent tooth decay or drink too much water which dilutes sodium in the body to dangerously-low or fatal levels. Or consider that many of the foods we eat everyday are suspected to have some causal connection to disease or unwanted conditions. It is therefore quite likely that making radical changes to our bodies undoubtedly will have surprising side-effects.

Is this reason enough to restrict human enhancement technologies, for the sake of protecting the would-be patient? The answer is not clear. Even if such technologies prove to be so dangerous or risky that we strongly believe we need to protect individuals from their own decisions to use those technologies (through paternalistic regulations), the well-informed individual might circumvent this issue by freely and knowingly consenting to those risks, thereby removing this reason for restricted use.

But even this case does not solve the conflict between freedom/autonomy and health/safety. First, it is not always clear whether a person's consent is sufficiently informed or not. For instance, consider a partygoer who may have heard that smoking cigarettes can be addictive and harmful but nonetheless begins to smoke anyway; this seems to be a less-informed decision than one made by a person with a parent whose smoking caused a specific and horrible illness (and associated expenses). Furthermore, the partygoer may be unduly influenced by peers or movies that glamorize smoking. So paternalistic regulations could be justified under some circumstances; e.g., where risks are not adequately communicated or understood, for children, and so on.

Second, the assumption that a procedure to implant some human enhancement technology may affect the health and safety of only that patient appears to be much too generous. Indeed, it is rare to find any human activity that has absolutely no impact on other persons, either directly or indirectly, such that our own freedom or autonomy is the only value at stake and clearly should be protected. For instance, opponents to regulating such activities as gambling, recreational drugs (including smoking tobacco), prostitution, segregation, and so forth commonly cite the need to protect their freedom or rights as the primary objection to those regulations. Yet, this objection ignores the opposing argument, which is that such activities may harm other persons, either actually or statistically.

To look at just one of many examples, at first glance, unfettered gambling seems to affect only the gambler (it is his money to win or lose, so the argument goes); but a broader analysis would point out that many gamblers have families whose bank accounts are being risked and that desperate gamblers may commit crimes to finance their addiction, never mind harms to the out-of-control gambler himself. Even marijuana use, which in many cases may be justified and allegedly harms no one, might be traced back to dangerous cartels that terrorize or bully the local population. Furthermore, irresponsible use of the drug could cause accidents or the user to neglect his or her obligations, family, etc. Notice here that we are not arguing that activities such as gambling and recreational drug use should be completely banned, but only that some measure of oversight seems to be appropriate for the sake of others, if not also for the welfare of the individual.

Relating back to the human enhancement debate, it seems premature to say that only the would-be enhanced person assumes any risk, even if the procedure does not affect his or her germline (i.e., cannot be passed on to the next generation). The harm or risk to others could also be indirect: Where steroids use by athletes sets the presumably-wrong example for children whose bodies and minds are still developing, we can anticipate a similar temptation to be created with human enhancement technologies among children. Even parents may feel pressure-or even an obligation - to enhance their children, which arises from the natural desire to want the best for our children or, in this case, make them the best they can be.

Third, even if the harm that arises from any given instance of human enhancement is so small to be practically negligible, the individual choices to enhance oneself can lead to aggregate harms that are much larger and substantial. For instance, in today's environmental debate, calls are increasing to limit 
activities from lawn care or drinking bottled water: on one hand, the amount of extra water needed to keep one's lawn green seems small, as is also the amount of fertilizer or pesticide that might leach into the groundwater, but the cumulative effect of millions of homeowners caring for a pristine patch of grass can be disastrous for a nation's water supply and health.

Likewise, as human enhancement technologies improve and are adopted by more people, the oncenegligible harms that arise from individual cases may metastasize into very real harms to large segments of society [38]. Life extension, as one case, may appear to be a great benefit for the individual, but on an aggregate scale, it could put pressure or burdens on families, retirement programs, overpopulation, and so on; we will return to this below.

\section{Fairness \& Equity}

Even if we can understand why there would be pressure to enhance one's self or children, it is important to note the following: advantages gained by enhanced persons also imply a relative disadvantage for the unenhanced, whether in sports, employment opportunities, academic performance, or any other area. That is to say, fairness is another value to consider in the debate. A related worry is that the wealthy would be the first adopters of human enhancement technologies, given that they can best afford such innovations (like LASIK eye surgery), thus creating an even wider gap between the haves and the have-nots [33].

In considering the issue of fairness, we need to be careful to not conflate it with equity. Under most economic theories, fairness does not require that we need to close the gap entirely between economic classes, even when justice is defined as fairness ([43]; for an application of Rawls to enhancement, see [1]). Indeed, there are good reasons to think that we want some gap to exist, for example, to provide incentives for innovations, in order to move up the economic ladder, and to allow flexibility in a workforce to fill vacancies and perform a wide range of tasks. At least some competition seems to be desirable, especially when resources to be allocated are limited or scarce and when compared to the historically-unsuccessful alternative of the state attempting to equalize the welfare of its citizens.

Thus, inequality itself is not so much the point, though any poverty or decline in welfare related to increased inequality may be a serious concern. We do not want people to stop striving to improve their own lives, even if the situation for others is not improved at the same time or ever. And natural advantages and inequities already exist unproblematically anyway; Hobbes recognized that these organic differences did not give any individual or group of individuals so much net advantage that they would be invulnerable to the "nasty, brutish, and short" conditions that mark human life [24].

Yet if human enhancement technologies develop as predicted, they can afford us a tremendous advantage in life; e.g., over others in a competition for resources, so much so that it overstretches the natural range of equality to the point where inequality becomes a more salient issue. This is where the gap between enhanced and unenhanced persons may be too wide to bridge, making the latter into dinosaurs in a hypercompetitive world. If we assume that the benefits of being an enhanced person must be largely paid from the welfare of others, e.g., a job-gain by one person is a job-loss by another, since the others are now at a relative disadvantage, this may impoverish the unenhanced, which would limit their access to such things as healthcare, legal representation, political influence, and so on.

Related to the notion of equity is that of fairness. Even if pronounced inequality is morally permissible, there is still a question of how an individual accesses or affords a human enhancement technology, which may be unfair or unacceptably magnify the inequality. If the distribution of or access to enhancement technologies is not obviously unfair, e.g., illegally discriminatory, then perhaps we can justify the resulting inequities. But what would count as a fair distribution of those technologies? A scheme based on need or productivity or any other single dimension would be easily defeated by the standard arguments that they overlook other relevant dimensions [44]. Even if a market system is considered to be fair or an acceptable approximation of it - which is highly contestable, especially after a fresh round of job layoffs and mortgage defaults-many still object to the unfairness of our starting points, which may date back to monarchies, aristocracies, "robber barons" (recall the saying that behind every great fortune there is a great crime), bad luck and other arbitrary circumstances [9]. And even if the starting points were fair, the subsequent market processes would 
need to be fair in order for the results (e.g., that only the wealthy can afford human enhancement technologies, who then gain significant advantages over the unenhanced) to be declared fair [32].

\section{Societal Disruption}

Fairness and equality are not just theoretical values, but they have practical effects. Gross inequality itself, whether fair or not, can motivate the worse-off masses to revolt against a state or system. But societal disruption need not be so extreme to be taken seriously. Entire institutions today-as well as the lack thereof - are based on a specific range of abilities and rough equality of natural assets. Sports, for instance, would change dramatically, if enhanced persons are permitted to compete to the clear disadvantage to unenhanced athletes, smashing their previous records. (This is not to say that sports should ban enhanced competitors, only that doing so would have a real, significant effect on careers and expend valuable resources to adjust sporting programs and contests; and in the end, it is not clear that sports is better off for its trouble or that which it has caused.)

Other institutions and systems include economic (jobs), privacy, communications, pensions, security, and many other areas of society. For instance, if lifeextension technologies can increase our average lifespan by 20 years (let alone the 100+ years predicted by some futurists $[10,28]$, and assuming that the extra 20 years will be a good life, not one bogged down with illness and unproductivity that afflict many elderly today), then we would need to radically adjust retirement programs: do we move the retirement age to 85 , which has negative consequences for job-seekers such as new tenure-track academic faculty, or increase contributions to pension plans, which puts pressure on household budgets and employers? Or both? Also, assuming birth rates do not decline (which causes problems of its own), longer lives will mean more pressure on resources such as energy and food, in addition to jobs, so this could disrupt society in negative ways.

Looking more into the distance, if enhancement technologies enable us to adapt our bodies to, say, underwater living (with implantable gills, flippers, echolocation, new skin, etc.), then we would need to construct new institutions to govern that lifestyle, from underwater real estate to pollution rules to law enforcement to handling electronic devices to currency (replacing paper money of non-waterworlds). Or if this sounds too far-fetched, consider humanity's rush into outer space that will require similar attention to be paid to such issues in the near future [29].

Other nearer-term scenarios that may cause social disruption include: a job candidate with a neural implant that enables better data retention and faster information processing would consistently beat out unenhanced candidates; a person with super-human hearing or sight could circumvent existing privacy protections and expectations by easily and undetectably eavesdropping or spying on others; more students (and professors) using Ritalin may grab admission or tenure at all the best universities, reducing those opportunities for others; and so on.

So societal disruption is a non-trivial concern and seems to be something we want to mitigate where we can, though this does not imply that we should resist change in general. Minimizing disruption might be achieve by transitioning laid-off workers immediately to a new job or job-training program, rather than allowing the layoffs to come unexpectedly which leaves the newly-unemployed with few options but to fend for themselves. Today, without this kind of preparation, we trust that these social and economic disruptions eventually will be handled, but there is still a real cost to those affected by layoff that could have been better mitigated. The typewriter industry, as an example, was blindsided by the fast-growing word-processing industry in the 1980 s, leading to the displacement of thousands of workers, both on the manufacturing and the end-users' sides. (Similar situations exist for the spreadsheet industry that displaced countless accountants and bookkeepers, the computer-aided design industry that displaced graphic artists, and so on.)

But, unless it will be clearly and seriously harmful, social disruption by itself does not seem enough to count as a strong reason against regulating enhancement technologies. After all, we do not wish that typewriters were never replaced with word-processing programs, though we hope the affected employees readily found gainful jobs elsewhere. Human enhancement technologies, likewise, do not necessarily need to be halted or regulated, but it seems more prudent and responsible to anticipate and prepare for any disruptive effects.

To be clear, there presumably will be benefits to society from enhanced persons. We can expect greater 
productivity or more creative and intellectual breakthroughs, which is why individuals would want to be enhanced in the first place. But what remains difficult to calculate is whether these gains outweigh the costs or risks, or even the likelihood of either gains or costswhich is needed if we do find it sensible to use a precautionary principle to guide our policymaking.

\section{Human Dignity}

The fiercest resistance to human enhancement technologies is perhaps a concern about their effect on "human dignity" and what it means to be human [42, 47]. For instance, does the desire for enhancement show ingratitude for what we have and (further) enable an attitude of unquenchable dissatisfaction with one's life? Some researchers suggest that discontent is hardwired into the genetic makeup of humans [23, 52], which is why we constantly innovate, strive to achieve and gain more, etc. However, even if this is true, it does not seem to be so much an argument to promote human enhancement technologies, but more a worry that those technologies are not the panacea or Holy Grail of happiness we might believe them to be; that is, we will still be dissatisfied with ourselves no matter how much we enhance ourselves (unless, of course, we somehow eradicate that part of our DNA that causes discontent).

Would human enhancement technologies hinder moral development? Many believe that "soul-making" is impossible without struggle [22], and achievements ring hollow without sacrifice or effort [42]; so if technology makes life and competitions easier, then we may lose opportunities to feed and grow our moral character. On the other hand, compare our lives today with pre-Internet days: increased connectivity to friends, work, information, etc. is often a double-edged proposition that also increases stress and decreases free time. This, then, raises the related concern of whether enhancement technologies will actually make our lives happier. (If the research mentioned above about discontent in our genes is accurate, then we might have a psychobiological reason to think not.)

Is the frailty of the human condition necessary to best appreciate life? There is something romantic about the notion of being mortal and fallible. But with existing pharmacology, we could eliminate the emotion of sadness today, and work is continuing on drugs that repress memories; but it is not clear that sadness (at least in the normal range, as opposed to clinical depression) is a "pathology" we should want to eliminate, rather than a human experience that we should preserve [42]. Other critics have suggested that life could be too long, leading to boredom after one's life-goals are achieved (e.g., [51]).

Finally, we will mention here the related, persistent concern that we are playing God with world-changing technologies, which is presumably bad [41]. But what exactly counts as "playing God", and why is that morally wrong; i.e., where exactly is the proscription in religious scripture? If we define the concept as manipulating nature, then we all have been guilty of that since the first man picked up a stick. Making lifeand-death decisions is a plausible candidate as a definition, but then physicians as well as soldiers (even in holy wars?) could be accused of this charge.

\section{Restricting Human Enhancement Technologies}

Given the preceding discussion, it should be clear that human enhancement is more than just about the individual's freedom or autonomy, but there are plausibly negative consequences on others and society that need to be considered. Or at least an argument needs to be made that freedom/autonomy trumps all other values, but such a position seems unnecessarily dogmatic. These issues point to the policy dilemma of whether we should have regulations or restrictions on human enhancement technologies, so to prevent or mitigate some of the negative impacts considered. Three answers suggest themselves: (1) no restrictions, (2) some restrictions, or (3) a moratorium or full ban.

A moratorium seems unrealistic to the extent that a worldwide one would be needed to truly stem the use of human enhancement technologies, and that no worldwide moratorium on anything has yet to work, including on (alleged) attempts to clone a human being. A local moratorium would send patients to "back-alley" enhancement clinics or to more liberal regions of the world, as is the case with "cosmeticsurgery vacations" in which those medical procedures are less expensive in other nations. Further, a ban on enhancement research seems to be much too prematurean overreaction to perceived, future risks - as well as a real threat to therapy-related research today.

On the other side of the spectrum, the idea of having no restrictions on human enhancement tech- 
nologies seems to be reckless or at least unjustifiably optimistic, given that there are plausible risks. As pointed out earlier, complete freedom or autonomy may be a recipe for disaster and chaos in any case; we do not want to grant the right to yell "Fire!" in a crowded venue or the right for dangerous felons to own firearms. ${ }^{4}$

So what about finding middle ground with some non-Draconian regulations? Critics have argued that any regulation would be imperfect and likely ineffectual, much like laws against contraband or prostitution [36]; but it is not clear that eliminating these laws would improve the situation, all things considered. Also, as a society, we still believe we ought to at least try to solve social ills, even if we cannot ultimately fix the entire problem, e.g., we cannot stop any given crime from ever occurring again, yet we still have laws against such acts. And even if there are practical reasons to not pursue regulations, would that send the wrong message; e.g., to children, that we countenance or support enhancement without reservations?

The issue of regulation will surely not be settled here, nor do we intend it to. Yet it is important to keep in mind that the human enhancement debate is not just a theoretical discussion about ethics, but it has bearing on the real world with policy decisions that may affect not just the would-be enhanced, but also researchers, manufacturers, social institutions, as well as our ideals of freedom and human dignity. ${ }^{5}$

\section{A Symposium on Nanotechnology \& Human Enahancement}

In the interest of exploring the above issues and others, we have put together five papers in the following symposium. These papers each take different perspectives on the enhancement debate, though all provide valuable contributions to it. The first paper is "Nanotechnology: Considering the Complex Ethical, Legal, and Societal Issues with the Parameters of Human Performance" by Linda MacDonald Glenn (Alden March Bioethics Institute/Albany Medical Center; University of Vermont College of Nursing)

\footnotetext{
${ }^{4}$ Perhaps even the right to be happy may be inappropriately exercised, say, at a funeral?

${ }^{5}$ For more about the general debate on regulation in nanotechnology, see [31].
}

and Jeanann S. Boyce (Montgomery College), provides more background and further examination of the many strands in the nanotechnology and human enhancement debate, particularly their link to relevant legal decisions and opinions.

Continuing the theme in law, the second paper, "Enhancing Justice?" by Tamara Garcia and Ronald Sandler (both of Northeastern University), begins to narrow our inquiry on the central issue of social justice, specifically asking whether human enhancement technologies would likely be justice-impairing or justice-promoting. They conclude that the associated challenges to social justice challenges cannot be remedied by technological design and innovation alone; rather, we must also address problematic features of social, political, and economic practices, policies, and institutions.

Our third paper, "Nanotechnology, Enhancement, and Human Nature" by Nicole Hassoun (Carnegie Mellon University), looks at another important, foundational issue: the relationship between humans and the natural world. Offering a more holistic discussion, it considers the possibility that human enhancement technologies may change, or even eliminate, the species Homo sapiens. The discussion draws from environmental ethics literature on the value of preserving species in asking whether such enhancing technologies are morally permissible or not.

Our fourth paper, "The Opposite of Human Enhancement: Nanotechnology and the Blind Chicken Problem" by Paul Thompson (Michigan State University), takes a novel, darker approach to the debate: It looks at the issue of dis-enhancing nonhuman animals, as is currently done for food production, to inform closely-related issues with engineering humans. This discussion sets the stage for not only deliberately handicapping bodies but also weaponizing or modifying them for someone else's ends [5].

Our fifth and final paper, "Ethics, Speculation, and Values" by Rebecca Roache (Oxford University), appropriately closes this symposium by responding to an important meta-question hanging over the entire debate: Are we squandering too much time in the human enhancement debate-at the expense of addressing more urgent, near-term issues with our limited research resources in ethics - on issues and scenarios that may or may not arise in the future? She 
makes the case that we are justified in our investigations, that human enhancement is a valuable area of inquiry.

Taken together, our aim is to provide a sense of how complex the human enhancement controversy is-from particular issues to justifying the entire debate itself - as well as the essential role nanotechnology will play here. These papers are not meant to cover the full range of issues, but they help illuminate key areas as well as offer perspectives not often heard in the debate.

Thank you, reader, for your interest in this escalating debate in science and society. We would like to also thank the US National Science Foundation for its generous support, under grant numbers 0620694 and 0621021. (Any opinions, findings, and conclusions or recommendations expressed in this material are those of the authors and do not necessarily reflect the views of the National Science Foundation.) We also thank John Weckert, editor of NanoEthics journal, as well as the authors of the papers that follow. Finally, we thank Marcus Adams for his editing assistance.

\section{References}

1. Allhoff F (2005) Germ-line genetic enhancement and Rawlsian primary goods. Kennedy Inst Ethics J 15(1):3956 doi:10.1353/ken.2005.0007

2. Allhoff F, Lin P, Moor J, Weckert J (2007) Nanoethics: The social and ethical dimensions of nanotechnology. Wiley, Hoboken, NJ

3. Allhoff F, Lin P, Moore D (forthcoming) Nanotechnology: what it is and why it matters. Malden, MA. Blackwell Publishing

4. Allhoff F, Lin P (2008) Nanotechnology \& society: Current and emerging issues. Springer, Dordrecht

5. American Association for the Advancement of Science (2006) Good, better, best: The human quest for enhancement. AAAS, Washington, DC

6. Bailey R (2005) Liberation biology: The scientific and moral case for the biotech revolution. Prometheus Books, Amherst, NY

7. Bostrom N, Roache R (2008) "Ethical issues in human enhancement". In: Ryberg J, Petersen TS, Wolf C (eds) New waves in applied ethics. Palgrave Macmillan, New York

8. Daniels N (2000) Normal Functioning and the TreatmentEnhancement Distinction. Camb Q Healthc Ethics 9:309322 doi:10.1017/S0963180100903037

9. de Balzac H (1835) Père Goriot (Signet Classics edition, 2004), trans. Henry Reed. New York, Signet Classics

10. de Grey A (2007) Ending aging: The rejuvenation breakthroughs that could reverse human aging in our lifetime. St. Martin's Press, New York
11. Dennis C (2004) Genetics: deaf by design. Nature 431:894 896 doi: $10.1038 / 431894 a$

12. Dyer C (2000) Surgeon amputated healthy legs. BMJ 320:332 doi:10.1136/bmj.320.7231.332

13. Edwards SD (2008a) Should Oscar Pistorius be excluded from the 2008 olympic games? Sports Ethics Philos 2:112 125 doi:10.1080/17511320802221802

14. Edwards SD (2008b) The Ashley treatment: a step too far, or not far enough? J Med Ethics 34:341-343 doi:10.1136/ jme.2007.020743

15. Freitas RA Jr (1998) Exploratory design in medical nanotechnology: a mechanical artificial red cell. Artif Cells Blood Substit Immobil Biotechnol 26:411-430

16. Friends of the Earth (2006) The disruptive social impacts of nanotechnology: issue summary. last access on 1 August 2008: http://nano.foe.org.au/node/151

17. Fukuyama F (2002) Our posthuman future: Consequences of the biotechnology revolution. Picador, New York

18. Fukuyama F (2006) Beyond bioethics: A proposal for modernizing the regulation of human biotechnologies. School of Advanced International Studies, Johns Hopkins University, Washington DC

19. Greely H (2006) 2005. "Regulating human biological enhancements: questionable justifications and international complications", The Mind, The Body, And The Law: University Of Technology, Sydney, Law Review 7: 87-110 (2005). Santa Clara J Int Law 4:87-110. joint issue

20. Guston D, Parsi J, Tosi J, (2007) “Anticipating the ethical and political challenges of human nanotechnologies" in Allhoff et al., 2007

21. Harris J (2007) Enhancing evolution: The ethical case for making ethical people. Princeton University Press, Princeton

22. Hick J (1966) Evil and the God of love. Harper and Row, New York

23. Hill SE (2006) Dissatisfied by design: The evolution of discontent (dissertation). University of Texas, Austin

24. Hobbes T (1651) Leviathan (penguin classics edition, 1982). Penguin Group, New York

25. Hughes J (2004) Citizen cyborg: Why democratic societies must respond to the redesigned human of the future. Westview, Cambridge, MA

26. Hurlbut W (2006) Opening remarks at "human enhancement technologies and human rights" conference, Stanford University Law School, 26-28 May 2006

27. Juengst E (1997) Can enhancement be distinguished from prevention in genetic medicine? J Med Philos 22:125142

28. Kurzweil R (2005) The singularity is near: When humans transcend biology. Viking Penguin, New York

29. Lin P (2006) Space ethics: Look before taking another leap for mankind. Astropolitics 4:281-294

30. Lin P, Allhoff F (2007) "Nanoscience and Nanoethics: Defining the Discipline" in Allhoff et al. 2007

31. Lin P (2007b) "Nanotechnology bound: evaluating the case for more regulation". NanoEthics 2:105-122

32. Lin P, Allhoff F (2008) "Introduction: nanotechnology, society, and ethics" in Allhoff et al., 2008.

33. McKibben B (2004) Enough: Staying human in an engineered age. Henry Holt \& Co, New York

34. Mielke J (2008) "Digital tattoo interface" entry at Greener Gadgets Design Competition 2008, New York, NY, February 
2008. Last accessed on 1 August 2008: http://www.core77. com/competitions/GreenerGadgets/projects/4673/

35. MIT (2008) Institute for soldier nanotechnologies website. Last accessed on 1 August 2008: http://web.mit.edu/ISN/ research/index.html

36. Naam R (2005) More than human. Broadway Books, New York

37. Nozick R (1974) Anarchy, state, and utopia. Basic Books, New York

38. Parfit D (1986) Reasons and persons. Oxford University Press, New York

39. Parviz BA, et al (2008) "Contact lens with integrated inorganic semiconductor devices" presentation at 21 st IEEE International Conference on Micro Electro Mechanical Systems, Tuscon, AZ, 13-17 January 2008

40. Persaud R (2006) "Does smarter mean happier?" in better humans?: The politics of human enhancement and life extension. Demos, London

41. Peters T (2007) “Are we playing God with nanoenhancement?" in Allhoff et al. (2007)

42. President's Council on Bioethics (2003) Beyond therapy: Biotechnology and the pursuit of happiness. Government Printing Office, Washington, DC

43. Rawls J (1971) A theory of justice. Belknap, Cambridge, MA

44. Rescher N (1980) "The canons of distributive justice". In: Sterba J (ed) Justice: Alternative political perspectives. Wadsworth, Belmont
45. Roco M, Bainbridge WS (2003) Converging technologies for improving human performance: Nanotechnology, biotechnology, information technology and cognitive science. Kluwer Academic, Dordrecht

46. Saletan W (2008) "Night of the living meds: the US Military's sleep-reduction program”, Slate, 16 July 2008. Last accessed on 1 August 2008: http:/www.slate.com/id/ 2195466/

47. Sandel M (2007) The case against perfection: Ethics in the age of genetic engineering. Belknap, Cambridge, MA

48. Savulescu J, Foddy B (2007) "Ethics of performance enhancement in sport: Drugs and gene doping". In: Ashcroft RE, Dawson A, Draper H, McMillan JR (eds) Principles of health care ethics. Wiley, London

49. Selgelid M (2007) "An argument against arguments for enhancement", studies in ethics, law, and technology 1: Article 12. Last accessed on 1 August 2008: http://www. bepress.com/selt/vol1/iss1/art12/

50. Thompson M (2008) “America's medicated army”, Time, 16 June 2008. Last accessed on 1 August 2008: http:// www.time.com/time/nation/article/0,8599,1811858,00. html

51. Williams B (1973) Problems of the self. Cambridge University Press, Cambridge, UK

52. Woodall J (2007) "Programmed dissatisfaction: does one gene drive all progress in science and the arts?". The Scientist 21(6):63 